Entrevista 



\section{Cibercultur@: informação, comunicação e co- nhecimento a favor do desenvolvimento social}

Cibercultur@: information, communication and knowledge for social development

Cibercultur@: información, comunicación y conocimiento por el desarrollo social

\section{Jorge A. González}

Entrevista concedida a Argemiro F. de Almeida* e Taís Aranha**

$\mathrm{N}$

a entrevista a seguir, o pesquisador mexicano Jorge A. González fala sobre o conceito de cibercultur@, criado em contraste ao de cibercultura, e a sua busca, por meio da pesquisa no campo da Comunicação, da apropriação e do uso mais humanizado e compartilhado das tecnologias, de forma a contribuir com o despertar de um outro mundo possível: um mundo de relações, mais justo, generoso e igualitário. Também destaca a utilização, pela primeira vez no campo da Comunicação, da epistemologia genética de Jean Piaget como uma poderosíssima ferramenta de investigação, e fala do aprendizado durante a sua estada no Brasil pelo período de seis meses, encerrada em abril de 2011.

* Professor de Filosofia, mestre em Comunicação Social pela Universidade Metodista de São Paulo (Umesp), coordenador do projeto de Comunicação da Associação Rede Rua, roteirista e diretor de vídeo. E-mail: argealmeida1@ terra.com.br

** Jornalista especializada em Jornalismo Social pela Pontifícia Universidade Católica de São Paulo (PUC-SP) e mestranda em Comunicação Social na Universidade Metodista de São Paulo (Umesp),. É diretora de Imprensa e Divulgação da Prefeitura de Suzano, na Grande São Paulo-São Paulo. E-mail: tais.aranha@ hotmail.com 
Revista Intercom - Quais são os teóricos que embasam o seu pensamento?

Jorge A. González - Eu sempre falo dos três primeiros livros que eu li em minha vida estudantil. $\bigcirc$ primeiro chamava-se "Educação como Prática da Liberdade”, de Paulo Freire (2001). No mesmo semestre, eu li "A Formação dos Símbolos nas Crianças", de Jean Piaget (1971) - eu não entendi nada, mas foi interessante porque é uma pesquisa empírica de Piaget, e também li de Norbert Wiener (1948) - "Cybernetics: or Control and Communication in the Animal and the Machine". Depois, foi muito interessante porque eu gostei muito de Comunicação, mas tinha algo que eu não gostava muito do curso, essa espécie de fascinação pela parte mais "fashion" da tecnologia. Então, eu pude fazer uma área de especialização em Sociologia da Educação, que abriu um universo interessantíssimo para mim, porque conheci muito cedo, pela mão do professor paraguaio Gilberto Gimenez, os trabalhos de Pierre Bourdieu. Foi como uma antecipação, porque Gimenez estudou na França, na Sorbonne, e conhecia o pensamento de Bourdieu. E aí começamos a ler os livros, em francês, em 1974 e 1975, quase no início do curso. Então, Bourdieu foi muito importante. Antes de Bourdieu, eu comecei a ler Antonio Gramsci. Mas Gramsci, que conheci também pela mão de Gilberto Gimenez, me conectou a um grande professor que teve muita influência na minha formação, também italiano: Alberto Mario Cirese, antropólogo cultural. Ele abriu para mim todo o universo das culturas populares, cultura hegemônica. Cirese me mostrou uma riquíssima reflexão sobre a maneira de observar a cultura, que é a especialidade de Gilberto Gimenez com seus estudos de Sociologia da Religião. Assim, comecei também a estudar Sociologia da Religião lendo Weber. Mudar do curso de Comunicação para Sociologia foi muito legal, porque continuava fazendo algo de produção para a televisão e rádio. Mas a minha formação começava a ser mais densa em alguns aspectos. Meu orientador iniciou-me com Robert Fossaert, Bourdieu, Cirese, a escola de sociologia francesa, a antropologia cultural italiana e também o pensamento antropológico mexicano, muito rico e muito antigo. Tive também essa leitura inaugural de Freire, que lembro bem, foi apresentado pela professora da aula como, interessante, 
mas como "um idealista". No curso de Comunicação, também tive professores muito bons, alguns dos quais eram formados nas principais universidades dos Estados Unidos, empiristas, excelentes para a pesquisa empírica e para fazer levantamento, outros excelentes professores de filosofia, de literatura. Nessa época, Comunicação era um curso com forte orientação humanista. A vida universitária foi muito estimulante e eu aproveitei tudo, quase morava na universidade, ao mesmo tempo cantava e tocava, para ajudar a pagar meus estudos na Universidade Iberoamericana. Eu cantava e tocava rock, blues... fazia muita música. Custeei boa parte do meu curso fazendo música - cantando, compondo, tocando e dirigindo musicalmente meus grupos. Acho que esta parte musical me deu muita versatilidade nessas minhas primeiras mergulhadas conceituais, especialmente frente às versões mais rígidas do marxismo. A universidade, quando eu passei de Engenharia Química para Comunicação, mudou completamente o seu sistema. Foi a primeira instituição acadêmica a ter um sistema departamental. Isso permitia fazer uma parte do curso em Comunicação e a segunda parte em outras disciplinas. Assim fui beneficiado e influenciado por vários excelentes professores dos departamentos de Letras (Noe Jitrik, Luis de Tavira, Ludvik Margulis), de Sociologia (Giménez, Luis Aguilar, Jesús García, Antonio Paoli, Maria Emilia Farias Mackey) e de Antropologia (Angel Palerm, Abraham Izaevich, Arturo Warman, Jorge Alonso). Com essas facilidades eu pude aproveitar muito e começar a orientar meus interesses de pesquisa para as culturas populares. Em minha primeira pesquisa (dominação cultural, expressão artística, promoção popular, 1980), estudei formas de comunicação camponesas e autogestão cultural por meio do teatro, e tive de aprender fazer etnografia da vida cotidiana, semiótica dos discursos, interpretação de estatísticas e técnicas teatrais para compartilhar com os jovens camponeses de Xalatlaco em 1975. Originalmente, eles queriam aprender fazer teatro, nós trocamos por técnicas de autogestão e expressão artística. Muito legal essa experiência, que me deu um grande estímulo para continuar estudando a cultura no mestrado de Sociologia das Culturas Populares, de 1977 a 1979. Depois, até 1980, na Universidade Metropolitana, no meu primeiro trabalho como professor e pesquisador, conheci Rolando Garcia Boutigue. 
Revista Intercom - O senhor trabalha com o conceito de cibercultur@ - escritacom arroba - e que nada tem a ver com o conceito tradicional de cibercultura, pois se trata de uma forma diferente de encarar a relação da sociedade com a tecnologia, a partir do sentido original do prefixo grego "kyber", que para você significa "autodeterminação escutante". Como e por que o senhor sentiu a necessidade de rever o conceito?

González - No âmbito social, eu acho que não tem se trabalhado suficientemente a interrelação entre três dimensões inseparáveis da ação humana: a informação, a comunicação e o conhecimento. Poderia dizer, embora não se fale assim, que na criação de qualquer sociedade a história tenha de passar necessariamente pela gestão e a organização dessas três ações. A dimensão simbólica de vida social, a criação dos contos que precisamos para viver, emerge das culturas de informação, de comunicação e de conhecimento. $\mathrm{O}$ interessante aqui é a caracterização operativa dos três conceitos para diferenciar o simbólico. O conceito de "ecologias simbólicas" teria uma integração maior do que a ecologia de informação, ecologia de comunicação e ecologia de conhecimento. Seriam dimensões analíticas para diferenciar isso. Não estamos usando o conceito mais comum de informação, nem o conceito matemático para calcular a probabilidade de um evento não esperado. Esses conceitos são arraigados como informação, mas eu prefiro entendê-la como a capacidade de estabelecer relações entre experiências e signos e, a partir daí, a outros signos mais complexos (textos, discursos). Porém, signo é uma relação, por isso cultivar a informação é uma capacidade de desenvolver um pensamento matricial. Lembremos que uma matriz em termos matemáticos é um sistema de relações. Então, o pensamento matricial implica um cultivo mais especializado, mais fino dessa capacidade elementarmente humana, para poder estabelecer relações significativas que permitem falar ou evocar eventos não presentes. Por isso é tão importante estudar Etologia, a comunicação entre os animais. Aprendemos atos humanos por meio deles. Os animais têm essa capacidade de coordenar ações, como se fala hoje, aqui e agora. Uma linguagem maravilhosa para resolver problemas imediatos, coordenações para caçar, para comer, para sobreviver e para estabelecer relações. Então é a ideia 
de refletir a informação como pensamento matricial e como essa capacidade de resolver também o pensamento sistêmico e próprio. Ainda estou trabalhando, não está totalmente definido, mas a comunicação não é como eu aprendi: falar, trocar mensagem etc. Antes disso, é a coordenação das ações. Quando o pessoal fixa a atenção não no intercâmbio de mensagem, mas o que possibilita o sentido do intercâmbio e a cultura do intercâmbio, a tensão concentra-se em uma organização, uma forma social. Então, os conceitos normais de comunicação não servem nesta primeira fase. Serve sim o conceito biológico de coordenação de ações. Porque na espécie humana, e até nos animais, o quadro para coordenar ações é uma forma de organização. Portanto, o conceito de comunicação que estamos buscando se põe assim, uma organização social. Por isso que falo que a forma social em que nos organizamos, que concordamos para desenvolver conhecimento, para relacionar coisas, fica investida, formatando o produto mesmo do conhecimento. Mas isso fica invisível, se nós aprendemos que a comunicação é um emissor que transmite e um receptor que recebe uma mensagem. Mas imaginamos que um emissor e um receptor não são pessoas, mas são lugares no espaço social. Ao compreender o emissor como um lugar no espaço social, as coisas mudam. A conceitualização da comunicação começa a se alterar, o que aparece ao receptor é algo como um iceberg enorme com superfície pequena. Isso significa, materializa e relaciona um olhar para a comunicação, que às vezes faz-se muito forçado fazer entender por meio dos conceitos normais da área de Comunicação. Para nós, é muito importante compreender a comunicação como um processo de coordenação de ações. $\mathrm{O}$ conceito de conhecimento, isso temos falado muito: convém entendê-lo como um processo mais que como um produto: como passar de um estado de menor conhecimento para um de maior conhecimento? Na primeira parte da cibercultur@como objeto de estudo, estamos utilizando categorias similares à tradição dominante, como tecnologias digitais e como melhor interagir com o computador para entender o que este vetor tecnológico, especificamente na comunicação que está sendo operada pelo computador, potenciada pelas comunidades locais, segue atuando com a nossa cultura de informação, nossa 
cultura de comunicação, que é nossa forma de organização, e a nossa cultura de conhecimento. Por isso eu falo que surge a famosa TIC [Tecnologia da Informação e da Comunicação], que sem um componente ausente operam como tecnologias castradas, mutiladas, porque não só são de informação e de comunicação, mas simultaneamente também são de conhecimento. E, ao não assumi-las como de conhecimento, perde-se um vetor forte de energia. Assim, volta-se às tecnologias como as tecnologias de desconhecimento, tecnologia de descomunicação, tecnologia de desorientação etc. E o que é pior: de distância social. As pessoas que perfeitamente poderiam operar essas tecnologias ficam afastadas, isto é, elas [as tecnologias] foram desenhadas para não conhecer. Isso para nós é interessante porque nos permite recolocar as perguntas. Vamos recolocar as perguntas pela interrelação, pela interdependência que há entre as tecnologias digitais - pela comunicação mediada pelo computador - e as ecologias simbólicas. A pergunta é esta: como é a interação entre as tecnologias de informação, de comunicação e de conhecimento da favela não sei o quê? Ou do sertão do Piauí? O que está acontecendo com essa ecologia simbólica e as tecnologias digitais (os celulares etc.) e a comunicação mediada pelo computador? E também tem que ver que estas ecologias simbólicas - de informação, de comunicação e de conhecimento - não podem ser trabalhadas sem um ecossistema de suportes materiais da informação, da comunicação e do conhecimento. Esses ecossistemas materiais geram, também, competências de informação, competências comunicacionais e de conhecimento - poderíamos dizer: uma cultura de informação, uma cultura de comunicação e uma cultura de conhecimento. Uma cultura com habilidade e capacidade para gerar conhecimento, para organizar e coordenar ações, com capacidade para conhecer ou desconhecer seu mundo. A essas capacidades chamamos de cultura, mas isso não pode ser sem as ferramentas, os artefatos culturais que nós chamamos de sistemas.

Revista Intercom - O senhor faz uma diferenciação interessante entre sistema de informação e o uso do computador. Seria possível explicitá-la? 
González - A diferença entre um monte de livro e uma biblioteca é um sistema de informação. Uma biblioteca é uma organização que você pode procurar. Não há computador que faça relações, e isso tem tanto poder! Basta olhar em "O Nome da Rosa" [Umberto Eco]. O personagem principal da biblioteca (o Jorge) era muito poderoso porque ele era o próprio sistema. Ele tinha todas as relações e quem entrava no labirinto morria, não dava para sair porque faltavam as relações. Essa diferença entre uma biblioteca e um monte de livro é o sistema de informações, e não um computador. Se você quer fazer melhores configurações de informação à mão é muito difícil, a complexidade mesmo dos processos, dos elementos, implica num monte de informação, e isso é muito bem facilitado pelo computador. Tem um vídeo que mostra como foi resgatada a Catedral Metropolitana da Cidade do México. É um documentário muito bem feito, tem uma parte que mostra como o pessoal, para salvar a catedral, inventa uma tecnologia de extração de lama do subsolo. A catedral está quebrando por causa da extração de água de um lago, porque a Cidade do México é construída acima de cinco lagos. Eles idealizaram que, se extraíssem a lama, a catedral voltaria a equilibrar-se novamente. $\mathrm{O}$ procedimento foi que eles pinçaram agulhas (sensores) em diferentes pontos, ligadas a um sistema de informação - a um computador -, que monitorava cada milímetro em quatro mil pontos. Como fazer isso, como governar (kyber) à mão? Não dá. Perdemos autodeterminação, o que seria, a catedral caiu, partiu-se. Nós conquistamos graus da autodeterminação, apropriando-nos de um sistema de informação profissionalmente. Essa capacidade de operar com a realidade por meio dos signos com as tábuas de correspondência é uma capacidade elementarmente humana. Como as tábuas de Hamurábi, o código de Hamurábi.

Revista Intercom - Há produtosna cibercultur@? Ecomo poderíamos denominar ou classificar o que é um produto em cibercultur@? González - O primeiro produto da facilitação desse valor de desenvolvimento são as comunidades emergentes de conhecimento como formas sociais de apropriação e cultivo da autodeterminação frente a problemas concretos. Isso tem de ser colocado dentro do 
segundo galho, um segundo ramo, o segundo aspecto de entender a cibercultur@como um contra vetor, como um valor de desenvolvimento social. Eu falo que desenvolver cibercultur@ restabelece, recria o tecido social destruído, distorcido historicamente, porque dá autoestima, autoafirmação, autoconhecimento, capacidade de lembrar, de esquecer autodeterminadamente pelas ferramentas autopoderosíssimas do sistema de informação. Mas um sistema de informação na mão de um tirano lhe dá uma ferramenta grave. Por isso, a condição de entrada de um sistema de informação tem de ser coletiva, generosa, humilde e compartilhada. A apropriação é coletiva, não individual. Eu poderia tomar como exemplo o comportamento de um cara do departamento de informática que é chamado por algum problema no computador, ele chega e diz: "ah, você, doutor"! Ele aperta uma tecla e pronto, sem ao menos dar qualquer informação sobre o ocorrido. Infelizmente, temos universidades que plantam isso. Resistência isolada não dá. Tem uma obra de Bertolt Brecht, "Um Homem é Um Homem". A primeira fala - se me lembro bem - é: "Esta é uma história de um homem que não sabia dizer que não; porque ser muito bom por si só não serve”. Mas não basta ser bom, há que ser bom e entender as relações sociais. Temos de ser bons, mas conectados. Desenvolver cibercultur@quer dizer desenvolver um processo de apropriação dos sistemas, das ferramentas ou de artefatos culturais, para dizer como Vygotsky. Artefatos culturais que vão nascer dos fornecedores, dos potencializadores de uma nova cultura de informação, uma cultura de horizontal de organização (comunicação) e uma nova cultura de conhecimento. Nas comunidades emergentes de conhecimento, o pessoal não tem que estudar Epistemologia ou ler a Wiener. Eles podem se apropriar com muito pouco de esforço das ferramentas para desenvolver suas culturas de informação, de comunicação e de conhecimento, porque elas são elementarmente humanas e eles começam a gerar a sua informação, a sua organização para construir e relacionar que um fato pode ser relacionado com outro fato e assim por diante. [Nesse sentido, se pode compreender a] experiência do Museu do Futebol [localizado no Estádio do Pacaembu, em São Paulo] como a museuografia que permite relacionar pessoas, eventos, lugares, tempos. Em Campina Grande (PB), na região da Borborema, eles 
têm um mapa grande, colorido, vermelho, verde etc., com todas as regiões e ecosistemas que eles desconheciam e agora têm um sistema de informação. Eles têm um calendário com as plantas medicinais, assim eles estão replantando com plantas locais desta parte do Nordeste. Eles sabem muito bem que na região há dois projetos grandes e muito diferentes uns dos outros. Um é a recuperação paulatina da agricultura familiar de subsistência; outro, a agricultura do monocultivo da agroindústria, que cria com o tempo ainda mais fome, que desenraiza as pessoas. Eles têm construído um calendário com as plantas, os nomes, os locais, nomes científicos que podem ser permanentemente lembrados. Os calendários, todos eles são um sistema de informação da humanidade poderosíssimo. O calendário que chamam de calendário dos índios do México, ou calendário Azteca - que nem é calendário, muito menos é dos aztecas -, é um sistema de informação poderosíssimo, com muitas coisas relacionadas, além de calendário dos dias, meses, anos. $\mathrm{O}$ fato é que eles [em Borborema] já têm desenvolvido um sistema de informação. Eu acredito, e depois vou tentar documentar esta hipótese, que do sistema educativo mexicano foi extraída paulatinamente a formação para a gestão da informação, e em especial para os setores mais pobres e despossuídos que frequentam a escola pública. Com esse mesmo pessoal que foi desenhado para ser objetos de estudo, quando eles se apropriam destas ferramentas, as coisas podem mudar. Mas comumente, sem a facilitação de uma estratégia de desenvolvimento de o que chamo de cibercultur@, eles não se reconhecem como tais, pois ficam restritos às informações pessoais, maioritariamente providenciadas e indicadas pelo sistema de difusão industrial que aqui no Brasil chamam de "midia", sem fermentação coletiva. Quando esta capacidade se volta ao coletivo, as bases da consciência rapidamente se conectam, porque desenvolvem uma maior capacidade de relacionar o passado, de redefinir o presente e de se abrir ao futuro. E esse é um novo produto. Eles deixam de ser somente narrados de fora para autonarrar os seus próprios contos, que vão encontrar contradições e conflitos com as definições, com os contos externos. Isso inicia um processo para desocupar o território simbolicamente ocupado e reocupá-lo com novas relações, coletivamente construídas. E aqui não estou falando só de 
"consciência”, o que acontece é maravilhoso, esse é um processo que os zapatistas fazem, sem nomeá-lo como sugere a teoria da cibercultur@. Por isso os produtos visíveis do desenvolvimento da cibercultur@se chamam de comunidades emergentes de conhecimento, local se trabalhamos com o povo, ou de investigação se num grupo sem professores e pesquisadores cuja função social é produzir conhecimento, mas não dentro de sistemas muito rígidos, conservadores e elitistas demais.

Revista Intercom - O senhor comentou que o movimento zapatista havia desenvolvido uma série de atitudes relacionadas à cibercultur@. Consegue fazer um paralelo para entendermos isso?

González - Existem os usos da tecnologia mais avançada à mão dos índios mais "atrasados" no México. São usos baseados ou derivados do seu processo de auto-organização, não somente como exército, mas como comunidade que tem linguagem intersubjetiva, linguagem que pode ser considerada como sistema modelante, primário do mundo. Pela linguagem, modelamos o mundo, estabelecendo diferenciações fonéticas e, depois, escritas. Eles têm uma estrutura linguística, um sistema modelante primário intersubjetivo, no qual "o outro" não é objeto, é sujeito. Essa parte estrutural da sua cultura fez com que eles se apropriassem de tecnologias dentro de uma forma de organização totalmente distinta. $O$ desenho estratégico da visibilidade midiática deles foi de primeira qualidade. Se não fosse por isso, estariam acabados, pois eles não têm armas, não têm balas - as armas eram de pau. Então, o "nós" - na fala fonética deles, "tik" - é central. Uma colega uma vez me disse que a estruturação de cibercultur@ é muito "índia”. Ela me presenteou com um livro autografado de Carlos Lenkersdorf, que se chama "Os Homens Verdadeiros", que é mais uma fonte de inspiração, porque na teorização e na pesquisa da cibercultur@ não estamos inventando nada novo, estamos retomando coisas elementares de muitos desenvolvimentos conceituais e práticos anteriores, como, por exemplo, escutar com empatia.

Revista Intercom - Há um elemento importantena cibercultur@ que não sei se podemos chamar de negação, mas entendemos que não 
é neste mundo globalizado, como está organizado, que acreditamos e buscamos praticá-la. Qual é este mundo que está por trás?

González - Escolhemos a palavra cibercultur@ contra vários colegas, que diziam que esta palavra servia para outra coisa, porque entendemos a tecnologia como um vetor, que tem origem e destino, é uma força com direção. Eu creio que todos os estudos que estão nascendo dessa relação entre a sociedade - particularmente, a dimensão simbólica, que eu chamo de "ecologias simbólicas" - e a interação com uma tecnologia, que nos dizem que é de informação e de comunicação, (mas também é de conhecimento), como falei antes, ao negar essa parte importante, convertem as TICs em tecnologias de desconhecimento. É uma afirmação temerária que vou fazer, mas se não reorientamos a base de organização e saber em um saber com outros, potenciado pelo desenvolvimento de uma cultura de informação, a orientação do vetor "vai dar zebra" - como aprendi da fala coloquial brasileira. As tecnologias, os aparatos que estão nesta tendência, neste vetor, não são inocentes, (tampouco são culpáveis) mas foram desenhados matricialmente para uso e apropriação individual. Poderiam também ter sido desenhados para propiciar apropriações no coletivo. Como aprendemos a utilizar a energia deste vetor a favor de uma sociedade que não seja excludente, individualista e suicida, o que é uma das maiores contradições do capitalismo? [Esta tecnologia, a da cibercultur@] tem efeitos cognitivos, sociais, psicológicos, biológicos importantes, e há uma série de estudos importantes que estão nascendo nessa direção. Porém, nós dizemos: estamos a um passinho para trás. Esta tecnologia individualizante [existente hoje] já supõe que nós temos de estar organizados de maneira individualizada, como numa carreira de cavalos. Em vez de inteligência distribuída, é a dispersão individualizante distribuída. Na cibercultur@, estamos experimentando, buscando essas duas coisas: esta interação entre as tecnologias digitais e a comunicação mediada por computadores para ajudar a mudar a ecologia de informação, a ecologia de comunicação e a ecologia de conhecimento de setores estratégicos da sociedade. Supomos que toda a sociedade, desde a pré-história até hoje, sempre teve a relação simbólica com estas três dimensões: a informação, a comunicação e o conhecimento. Parece-nos errôneo 
falar hoje de "sociedade de conhecimento", pois nesse sentido toda sociedade (e não só esta) é (e tem sido sempre) de conhecimento, de informação e de comunicação. Trabalhamos sobre isso permanentemente. A cultura da informação é uma cultura, um cultivo autodeterminante de relações. Mostrar a nossa capacidade para estabelecer vínculos entre experiências, signos, códigos, porque se posso compartilhar a informação, não a perco, é maravilhoso! Essa capacidade é fundamental, porque a partir dela podemos pensar, inventar metalinguagens e não mais linguagens-objeto, mas linguagens que falam de linguagens, quer dizer, metalinguagens. Essa ideia de trabalhar informação é central na cultura da comunicação, todo mundo segue pensando que a comunicação é compartilhar mensagens. Sim, é, compartilhar mensagens, é fluxo de informação. Porém, isso implica em ter um emissor e um receptor, é o que se vê da superfície, mas debaixo disso há um iceberg enorme de relações sociais objetivas, independentemente da vontade, do conhecimento e do gosto dos que estão nelas. Então, é um erro o excesso de concentração dos estudos de Comunicação na parte de cima do mar, que é a parte que se pode descrever: a festa tal, o conteúdo do periódico tal. Isso é muito interessante, é preciso fazê-lo, porém, a compreensão, a explicação do por que é assim o que escreveu está no nível interobjectual, há que se passar pelas relações, construir as estruturas para poder entender o por que é assim e não de outra maneira. E, para poder entender as estruturas, necessariamente há que se entender os processos pelos quais, na história, esta estrutura passou no movimento. Essa fotografia da estrutura me explica o que se pode ver de momento, mas isso vai mudando, e muda porque vão se alterando as relações, que não são vistas. Aí entra o importante: as relações que não vemos, que pautam as interações. A cultura da comunicação não está, para nós, no que se disse, nem nas mensagens, nem nos receptores, nem nos canais, nem nas tecnologias. Está por debaixo delas, na forma social em que estamos organizados para conversar. $\bigcirc$ que não se pode ver são as relações, há algo nas relações que estão operando e não as vemos e nada mais. Uma comunidade emergente, um grupo, desenvolve sua cultura de comunicação quando é capaz conversando, aproveitando essas extensões de objetivar o que 
não é "objetivavel" aparentemente, porque é objetivo, independentemete da sua vontade e gosto. $\mathrm{O}$ que não se pode ver são as relações que estão estabelecidas. Pela psicologia genética sabemos que cognitivamente, só vemos objetos, recortamos objetos, mas não vemos as relações, há que construí-las, inferi-las. Quando numa relação, a estrutura sou eu, não me dou conta do risco e, com a melhor das intenções, (e esta pode ser uma "boa" pessoa). Não tem que ser boa pessoa, ou melhor, não basta ser uma boa pessoa, tem de entender estas relações. Nas relações humanas, quanto maior for a diferença entre as pessoas, mais provável aparece a estrutura oculta.

Revista Intercom - Quais são os conhecimentos estratégicos para mediarum processo de cibercultur@?

González - Especialmente os de cultura de comunicação. Tem de ter claro conhecimento de que há uma estrutura subjacente (ou suprajacente) que é a que produz os comportamentos que observo. Ao conhecer que o que vejo é uma aparência, há que se ter conhecimento para alterar não só a conduta, mas alterar a relação. $\mathrm{O}$ mediador tem de ser um facilitador energético, fazer com que a energia do grupo flua em novos tubos, novos canais que não sejam os banhos carrapaticidas [referindo-se à maneira como as carteiras são dispostas numa sala de aula, uma atrás da outra, como animais numa fila para o banho carrapaticida], que produzem medo ao erro, medo a ficar mal, medo a diferir-se, porque a diferença faz com que fique mal. Quando trabalho com grupos, não intervenho no conteúdo, pois um mestre ou um professor já traz uma carga, e já convivi com muitos que se especializaram em nunca se equivocar. A cultura de conhecimento é a cultura de aprender como passamos de um estado de menor diferenciação a um de maior diferenciação; de não ver suas relações, a vê-las.

Revista Intercom - O senhor traz para a ciência da Comunicação a Epistemologia Genética de Jean Piaget e Rolando García, para explicar que os processos e os mecanismos de construção da ciência se assemelham aos processos cognitivos humanos. Como se fundamenta este conceito? 
González - Do ponto de vista da Epistemologia Genética, não se tem trabalhado sobre Epistemologia da Comunicação. Há outras epistemologias da Comunicação, a maior parte delas filosóficas, especulativas. Isso não é um defeito, é uma qualidade. A filosofia especulativa é a mãe, a geradora de toda a ciência - e também a castradora das ciências, na história tem estes dois papéis que só podem ser visto num processo. Às vezes, a Filosofia empurra a ciência adiante; às vezes, são afastadas e inimigas; às vezes, há uma tensão dialética muito interessante. Em termos de disciplina, não há na Epistemologia Genética uma Epistemologia da Comunicação, da disciplina de Comunicação. Há outras perspectivas, como a de Manuel Martín Serrano, um grande investigador espanhol, mas infelizmente pouco conhecido entre nós. Coordenados por Rolando García, há mais ou menos um ano e meio estamos trabalhando na Epistemologia da Ciência "Social", quando a ciência se aplica na sociedade, aos objetos sociais. A Epistemologia Genética nos ajuda a melhorar nossa estratégia metodológica, pois sabemos que o que escrevemos e construímos tem de ser "construível” em outro nível de processos estruturais, e as estruturas que teremos são efeitos de tensões, de organizações, de desorganizações no tempo. Uma estrutura é um sistema de transformações. Esta ideia de entender dialeticamente o conhecimento vem diretamente de Marx, de Piaget e de Rolando Garcia, entendendo-o como um sistema complexo. Até agora, parece que a ciência aplicada ao uso da comunicação está demasiado concentrada em descrições, em aparências, na parte conceitual, e tem pouca elaboração conceitual densa, que ajude a entender as possibilidades, e tem também de crescer nos processos intra-objectuais, inter-objectuais e transobjectuais. Quando uma ciência chega aos mecanismos transobjectuais e objetiva-os, é porque esta ciência ou disciplina já é capaz de representar processualmente o que não se vê. Ao fazê-lo, o olhar do cientista se enche de relações. É o poder da teoria: uma teoria ajuda a dotar-se de relações. Não conheço outro trabalho de Epistemologia Genética de origem piagetiana sobre a Comunicação.

Revista Intercom - Fazer ciência é também uma forma de fazer militância? Ou é possível separar isso? 
González - Inseparável para mim. Fazer ciência é uma forma de militância sim, porque é um ofício que se propõe a desmontar, desconectar, desligar interpretações que nos vieram de sempre, e preencher, adotar relações das quais nós somos verdadeiramente responsáveis. Não é ganhar ego ou fama, é ganhar graus de autodeterminação. Quando desta autodeterminação se constrói "tík", é mais ouvinte e menos falante. Há um poema que gosto muito de León Felipe: "não se trata de chegar primeiro que todos e antes que ninguém, se não chegar a tempo e todos juntos”. E, depois, que a ciência nos ajude a desenhar novos, possíveis e melhores mundos, não piores. Não podemos separar a ciência dos usos sociais da ciência. Se a ciência que produzo serve para perder graus de autodeterminação e para fechar os mundos para o futuro, esta ciência não segue. No México, participo da Associación de Científicos Comprometidos con la Sociedad", uma organização que luta contra à ciência instrumentalizada e submissa, por isso a militância tem de facilitar processos de comunidades emergentes de investigação que abandonem o seus cômodos banhos carrapaticidas.

Revista Intercom - O senhor esteve no Brasil por seis meses, de outubro de 2010 a março de 2011. A estada no Brasil valeu a pena? Como ficam agora os projetos iniciados a partir de seu incentivo? González - Ficam ótimos, tem sido uma instância acadêmica de primeira ordem. Tive a possibilidade de visitar os Estados Unidos passeando, mas eu quis ficar aqui, porque os processos da sociedade brasileira têm sido muito interessantes nos últimos tempos. Eu acho que a capacidade organizativa que tem a sociedade brasileira é muito interessante. Aqui tenho encontrado experiências de organização social, política, cultural, que não vamos falar que são inéditas no México, mas o meu país tem sofrido uma desestruturação social muito forte. Isso é um dos problemas graves do narcotráfico, eu acho que é quase um Estado falido. A falência do Estado perante todos, porque o pessoal que faz o narcotráfico, que recruta outros para o tráfico, é um pessoal jovem que tem sido desfavorecido durante séculos, tem sido depreciado, sem possibilidade de fazer outra coisa. Por essa mesma razão, eu aceitei com prazer vir para cá. Conheço os trabalhos de Cicília 
Krohling Peruzzo, que são muito importantes, uma experiência de comunicação comunitária única, muito linda e constante. Cicília tem anos trabalhando [com grupos populares no Espírito Santo e na Favela de Heliópolis, na periferia de São Paulo], não é por acaso que é uma autoridade conhecida, além de seu jeito especial de lidar com as pessoas e como intelectual que é. Estamos agora idealizando e já foi aceito um livro novo sobre Metodologia, que sairá pela Editora Vozes, no qual buscamos fazer essa aproximação entre a Epistemologia Genética e a Metodologia de pesquisa. Em muitas partes do Brasil onde eu estive aprendi muito, e também a prática de apresentar (em fluido "portunhol") para outros que não falam a minha língua todo esse conteúdo que eu tenho pensado em espanhol. Às vezes, tenho de fazer um esforço enorme para me comunicar, "portunholizá-lo", isso tem ajudado muito. Acho que tenho compreendido e até mesmo melhorado muito as minhas ideias, contrastando, confrontando com entendimentos diferentes, com experiências distintas. Cada um de vocês tem experiências interessantíssimas, isso é um tesouro. Para mim, a relação não é a de um professor ensinando, sei que tenho algumas coisas mais ou menos claras, e se for possível ajudar alguns de vocês em seus processos, ficarei encantado. Não porque fui eu quem as revelei, mesmo porque eu também aprendi de outros muito bons que se ocuparam de se fazer claras as suas ideias. Para mim, isso tem sido um desafio interessante. Até o momento, não escrevi muito ainda sobre a experiência no Brasil, só tomei notas, mas não era para isso, era para aprender, para estimular, para conectar-me. Estou contentíssimo. E também essa tentativa que fiz, e está dando certo, de conectar as comunidades emergentes do México, especialmente lá, com os indícios que estão nascendo aqui no Brasil: as comunidades emergentes de investigação e de conhecimento local que estão nascendo aqui.

Revista Intercom - Direcionando o olhar para o que o senhor visitou e observou no Brasil, nos vários ambientes, em suas diversas dimensões, na rua, nos projeto ou na academia, percebe se haveria lugar para se fazer as perguntas que a cibercultur@se propõe a fazer nesses espaços? 
González - Acho que sim. Com uma estrutura de relações, como acabamos de falar, com uma cultura de organização, uma cultura de comunicação, de informação e de conhecimento diferentes, nesse sentido, sim. É claro que os ajustes devem ser feitos, porque o conceito que estamos trabalhando em cibercultur@ ainda se encontra no início de uma concepção teórica rigorosa, aberta, mas que também pode ser útil. Ou mesmo do lado da cibercultur@para ser utilizada, trabalhada como objeto de estudo para pensar essas relações múltiplas, diferentes e contraditórias entre as tecnologias digitais e da comunicação mediada pelo computador, como as ecologias simbólicas de informação, de comunicação e de conhecimento, dá muito bem para isso.

\section{Quem é Jorge González}

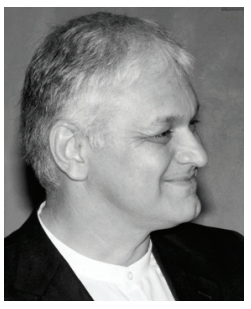

Mexicano, Jorge A. González é membro do Sistema Nacional de Pesquisadores desde 1987 e catedrático Unesco de Comunicação 2000 na Universidade Autônoma de Barcelona, na Espanha. Foi tinker professor da Universidade do Texas (2002), nos Estados Unidos, e membro da Academia Mexicana de Ciências (2008), jurado do Prêmio Nacional de Jornalismo (2009); avaliador do Sistema Nacional de Pesquisadores (2011), membro do Conselho de Desenvolvimento Cultural do Distrito Federal (2009). Coordena, junto com Rolando García Boutigue, o Programa de Pesquisa Epistemologia da Ciência e Cibercultur@, no Centro de Investigações Interdisciplinares em Ciências e Humanidades da Universidade Nacional Autônoma do México (UNAM) desde 2004. É também coordenador do LabCOMplex - Laboratorio de Investigación y Comunicación Compleja / Programa de Epistemología de la Ciencia y Cibercultur@/ Centro de Investigaciones Interdisciplinarias en Ciencias y Humanidades (CEIIH) da Universidad Nacional Autónoma de México, Ciudad de México-DF. Foi fundador e coordenador por 16 anos do Programa Cultura, da Universidade de Colima, fundador e coordenador do Laboratório 
de Comunicação Complexa da Universidade Iberoamericana, na Cidade do México (2001-2003), e co-fundador da Rede de Pesquisas e Comunicação Complexa. Em 1990, ganhou o 1ํㅡㄹ Concurso Mundial de Jovens Sociólogos (ISA, Madri, Espanha). Publicou: "Sociología de las culturas subalternas", Mexicali, UABC (1990); "Mas(+) cultura(s). Ensayos sobre realidades plurales", México, CNCA (1994); "Entre cultura(s) y cibercultur@(s). Incursiones y otros derroteros no lineales", La Plata: EDULP (2008); "La cofradía de las emociones (in)terminables: miradas a las telenovelas en México", Universidade de Guadalajara, México (1998); Cultural fronts: towards a dialogical understanding of contemporary cultures, in: Lull (Ed), "Culture in the communication age", London, Routledge (2001); "Cultura(s) y Cibercultur@(s)”, UIA (2003); "El desarrollo de Cibercultur@en proyectos de conocimiento: hacia una comunidad emergente de investigación”, ALER (2007); "Cibercultur@ e iniciación en la investigación”, CONACULTA-IMC-CEIICH (2007); "De la cultura a la Cibercultur@”, Argentina, EDULP (2008); e "Digitalizados por decreto: desarrollo de cibercultur@ o inclusión desigual forzada para América Latina” (2008), entre outros. Prepara "La Formación de las Ofertas Culturales y sus Públicos en México (FOCYP): teoría y metodología”; e (Ed.) "De historias con minúsculas y oficios familiares en Colima: una mirada fractal para mirar el siglo XX". Trabalha atualmente em projetos de pesquisa e desenvolvimento de Cibercultur@ a partir das ecologias simbólicas do México e da América Latina. Entre 2010 e 2011, foi pesquisador visitante da Universidade Metodista de São Paulo, como bolsista da Fundação de Amparo à Pesquisa do Estado de São Paulo (Fapesp), no Brasil. 